\title{
Do expert clinicians make the best managers? Evidence from hospitals in Denmark, Australia and Switzerland
}

\author{
Agnes Bäker, ${ }^{1}$ Amanda H Goodall (i) 2,3
}

'Department of Business Administration, University of Zurich, Zurich, Switzerland ${ }^{2}$ Bayes Business School (formerly Cass), City, University of London, London, UK ${ }^{3}$ IZA Institute of Labor Economics, Bonn, NordrheinWestfalen, Germany

Correspondence to Dr Amanda H Goodall, Management, Cass Business School, London, UK: Amanda.Goodall.1@city.ac.uk

Received 6 March 2021 Accepted 30 July 2021 Published Online First 12 August 2021

\section{Check for updates}

(c) Author(s) (or their employer(s)) 2021. No commercial re-use. See rights and permissions. Published by BMJ.

To cite: Bäker A, Goodall AH. BMJ Leader 2021;5:161-

166.

\begin{abstract}
Introduction Hospital quality rests on the morale and productivity of those who work in them. It is therefore important to try to understand the kinds of team leaders that create high morale within hospitals.

Methods This study collects and examines data on 3000 physicians in hospitals from Denmark, Australia and Switzerland. It estimates regression equations to study the statistical predictors of levels of doctors' job satisfaction, their intentions to quit or stay in their current hospital and their assessment of the leadership quality of their immediate manager. A particular concern of this study is to probe the potential role played by clinical expertise among those in charge of other physicians.
\end{abstract}

Results When led by managers with high clinical expertise, hospital physicians are (1) more satisfied with their jobs, (2) more satisfied with their supervisors' effectiveness and (3) less likely to wish to quit their current job. These findings are robust to adjustment for potential confounders, including age and job seniority, and pass a variety of statistical checks (including clustering of SEs and checking for omitted variable bias). They are replicated in each of the three nations.

Conclusion Physicians are happier with their jobs when led by outstanding clinical experts. It is not sufficient, it appears from this evidence, for leaders merely to be clinicians. This suggests that-though only an idealised and presumably infeasible randomised experiment could allow complete certainty - there is a natural case for managers within a hospital hierarchy to be drawn from the ranks of those who are themselves outstanding clinicians.

\section{INTRODUCTION}

A burgeoning recent literature has examined the importance of the professional background and qualifications of hospital Chief Executive Officers (CEOs) and their governing boards. ${ }^{1-6}$ However, relatively little is currently known about the role of hierarchies among medical doctors, here called physicians, inside hospitals. This article probes the characteristics of successful leaders within a hospital hierarchy. Specifically, it addresses the following question: which clinicians seem to make the best supervisors and managers of other physicians (ie, the best 'line managers')?

In healthcare as well as other settings, those who occupy middle management positions are known to influence employees' attitudes. ${ }^{7-10}$ Job satisfaction not only reflects worker well-being ${ }^{11}$; it also influences individual productivity, ${ }^{12-14}$ employee quit intentions ${ }^{15}$ and burnout rates. ${ }^{16}$ Clinician job satisfaction and consequent performance might be viewed as particularly important because it is known to affect patient outcomes. ${ }^{17} 18$

This study assesses the influence that supervisory physicians (those who act as line managers) have on the job satisfaction and quit intentions of the physicians they lead. Importantly, it identifies clinical expertise as a key characteristic associated with effective physician managers. Leadership behaviour is examined through the lens of so-called transformational leadership, which places emphasis on motivating followers through shared values to commit to common goals. Assessed transformational leadership behaviours include a line manager's ability to communicate a clear and positive vision; whether staff feel they are empowered, encouraged and developed; if managers engage in innovative thinking; and, finally, whether they lead by example.

\section{METHODS}

This article combines data from hospitals in three countries obtained through online surveys. One aim was to try to identify common, rather than merely country-specific, patterns.

Sample 1 consists of physicians working in 40 hospitals in Denmark, whom we surveyed at the end of 2018 and the beginning of 2019. Sample 2 is of physicians working in 15 hospitals in Australia. They were also surveyed in 2018. Lastly, sample 3 covers physicians working in three universityaffiliated hospitals in German-speaking Switzerland, whom we surveyed in 2017. The surveys were in English, and for the Swiss sample additionally in German.

Several organisations collaborated with us. For sample 1, the Organization of Danish Medical Societies sent out the survey link to their members. For sample 2, the South Australian Salaried Medical Officers Association sent out the link. In the case of sample 3, the medical director at each hospital sent the survey link to all physicians employed at the hospital. Up to three reminders were sent, with 1-2 weeks in between.

For sample 1, we received 4451 responses (ie, a response rate of 22\%). For sample 2, we received 504 responses (ie, a response rate of $28 \%$ ), and for sample 3, we received 514 responses (ie, a response rate of 29\%). The final samples in the following analysis are smaller because (1) we restricted samples to physicians with at most 77 years of age and (2) we dropped cases where physicians 
indicated their line manager supervised more than 50 physicians and (3) due to some incomplete responses. Our survey response rates are normal in human resources (HR) research. ${ }^{19}$ They are consistent with online surveys yielding lower response rates than postal surveys or person interviews. ${ }^{20}$

Our dataset contains hospitals from three countries, and importantly, the sample includes a broad cross section of hospital types. The Swiss physicians in sample 3 all worked at hospitals that are affiliated with a university, are prestigious and are ranked highly in an employer-attractiveness league table. The Danish and Australian samples include a broad mix of hospitals with respect to university affiliation, hospital prestige, size of hospital and urban/rural location. We estimate effects across different types, thereby helping to ensure that our results capture what is true overall.

\section{Variables and measures}

We were interested in three ways of measuring the physicians' well-being and job fulfilment at their workplaces. These covered (1) their satisfaction with the job, (2) their intention to stay or quit their current workplace and (3) their assessment of the leadership behaviour of their line manager. As might perhaps be expected, the patterns found later in the regression equations are similar across all three measures.

\section{Job satisfaction}

We measured physicians' satisfaction with their job with both a single-item job satisfaction variable and with a multi-item job satisfaction scale. The single item for job satisfaction (see, eg, Wanous et $a l^{21}$ for this to be equally valid as a multiple-item scale) is 'Overall, how satisfied are you with your job?' Respondents could answer the question on a 6-point Likert Scale from 'Very dissatisfied (1)' to 'Very satisfied (6)'. In sample 2 and a randomly drawn half of sample 3, we also collected the generic job satisfaction scale (Macdonald and Maclntyre, ${ }^{22} 10$ items). Items of the scale include 'I receive recognition for a job well done' and 'I feel close to the people at work'. They were rated on a 5-point Likert Scale from 'Strongly disagree (1)' to 'Strongly agree (5)'.

\section{Quit intention}

We measured physicians' intention to quit their job with a single item. The question was 'Have you considered leaving your organisation?' Respondents could answer the question on a 5-point Likert Scale with 'Yes, in the last month (1)'; 'Yes, in the last 6 months (2)'; 'Yes, in the last year (3)'; 'Yes, but not for a long time (4)'; and 'No (5)'. Thus, to allow for consistent interpretation, we capture quit intention inversely, with highest values referring to a low quit intention (or a strong intention to stay).

\section{Leadership behaviour}

We measured line managers' leadership behaviour using the Global Transformational Leadership Scale. ${ }^{23}$ This scale includes seven items that summarise specific leader behaviours: (1) communicates a vision, (2) develops staff, (3) provides support, (4) empowers staff, (5) is innovative, (6) leads by example and (7) is charismatic (Carless et al, ${ }^{23}$ p390). Items include 'My immediate senior communicates a clear and positive vision of the future' and 'My immediate senior treats staff as individuals and supports and encourages their development'. They were rated on a 5-point Likert Scale from 'Rarely or never (1)' to 'Very frequently, if not always (5)'. The effectiveness of a manager is assessed by the scores obtained across the seven items; higher values of the index correspond to a more 'transformational' type of leadership.

\section{Clinical expertise of the physician's line manager}

We measured perceptions of line managers' clinical expertise by asking respondents to please mark the appropriate answer: My immediate senior is (1) 'a highly distinguished clinician', (2) 'a distinguished clinician', (3) 'an averagely able clinician', (4) 'not that interested in clinical work', (5) 'not a clinician' and (6) 'others (please specify)'. To create the main explanatory variable for use in later regression equations, the top-two categories were combined into a single dummy variable. When responses were marked in the first or second category, the physician's line manager (ie, the immediate senior, which a footnote in the questionnaire specified to refer to, eg, registrar, consultant, head of the unit/department, clinical/medical director or $\mathrm{CEO} /$ executive director) is classified in the later analysis as an expert clinician.

There were three reasons why we collected subordinates' views of their managers' expertise. First, a growing body of literature finds that, although supervisors' and subordinates' perceptions can differ ${ }^{24}$ and HR policies and employee perceptions thereof differ, ${ }^{25}$ it is subordinates' perceptions that matter for their job satisfaction. ${ }^{26}$ Thus, by eliciting subordinates' views, we capture a crucial variable for their well-being and enjoyment at work. Second, as the physicians in our samples work on stressful tasks in close-knit teams, it is likely that the physicians are knowledgeable about the expertise of their line manager (indeed they are, arguably, the ones most qualified to judge). Third, anonymity concerns prevented us from literally asking the responding physicians for the name of their line manager to allow us to make our own assessment of the manager's clinical background.

\section{Demographical variables}

We adjusted for variables that are likely to relate to workers' satisfaction and perceptions of leadership behaviour. Specifically, we controlled for the respondents' job positions and hierarchy level (ie, positions such as resident, fellow and attending in the US system; see ${ }^{27}$ for a meta-analysis on the link between job level and job satisfaction). Furthermore, we controlled for the number of years in the current position (years in position) as that might relate to inherent frustrations about promotion, the perceptions of the line manager and overall job satisfaction. We also adjusted for the number of hours worked in an average week, which we expect to relate negatively to job satisfaction for a population of hard-working doctors. Furthermore, we adjusted for typical demographics, namely, age and gender.

In the Danish case (sample 1), we also had an empirical measure of how happy our respondents said they were with their home life (satisfaction with life at home). We were able to use that, in the regression equations for Denmark, to adjust for 'Pollyanna' effects in which inherently cheerful individuals potentially give high (inflated) scores for everything, including possibly both for their own job satisfaction and the clinical prowess of their manager. We viewed this as an important final check.

\section{Analysis and estimation}

The principal aim of the study was to examine statistically the relationship between managers' clinical expertise and their subordinates' levels of job satisfaction, intention to quit and perceptions of transformational leadership behaviour.

We apply ordinary least squares (OLS) regression equations in which a variety of independent variables are used as predictor 
variables. Technically, OLS regression imposes cardinality on a dependent variable. However, conducting ordered estimators produced the same substantive conclusions, so the simpler OLS findings are presented here.

Due to anonymity and confidentiality concerns, we were unable to elicit identifiers for the line managers. This means that in the empirical estimation, we cannot adjust for inter-rater correlations. Thus, it is not possible in the regressions to allow for so-called team or line manager fixed effects. Nevertheless, a check on that potential issue can be done. It exploits information on where physicians are working and in which particular position. We generated broad clusters of respondents who were likely to be reporting on the same line manager, because they work at the same hospital and in the same job position, for example, at the same hierarchical level. ${ }^{28}$ For sample 3, having surveyed three hospitals and having no way of identifying the individual hospital each time, we generated 'clusters' using job position and gender of the line manager. We used these to cluster SEs, thereby accounting for the possibility that ratings of line managers by respondents within the same cluster might not be independent. For lower hierarchy levels especially, some of these clusters may assume interdependence where there truly is none, thus providing us with a conservative estimate of the hypothesised relationship between line managers' clinical expertise and subordinate doctors' job satisfaction.

There is still one way that regression results might be affected by a single-rater bias or common method variance. To reduce the likelihood of a bias, we used the survey design (order of questions and question format) suggested by Podsakoff et al. ${ }^{29}$ Specifically, we deliberately asked about physicians' feelings about their job before mentioning anything about their immediate manager. Thus, we first measured the dependent variables 'job satisfaction' and 'intention to quit'; second, we asked these physicians for their assessments of their line managers' transformational leadership behaviour; and finally, we collected physicians' perceptions of their line managers' clinical expertise.
We also- to avoid any linkage in the minds of the physicians answering-deliberately varied the question formats for job satisfaction and clinical expertise.

As explained earlier, a further check was, in the case of Denmark (sample 1, where the data were available), to include an independent variable for a person's expressed satisfaction with their life at home. This acts to pick up, and correct for, omitted cheerful personality types.

\section{RESULTS}

Table 1 displays the descriptive statistics, correlations and coefficient alphas of our main variables for all three samples (Denmark, Australia and Switzerland). Descriptive statistics for the demographical variables are given in table 2.

Tables 3-5 report the article's main results presented as OLS regression equations to explain, respectively, the job satisfaction of physicians, their likelihood to quit and their assessment of their manager's leadership behaviour. Table 3 gives regression equations for Denmark (sample 1); table 4 is for Australia (sample 2); table 5 is for Switzerland (sample 3). The three sets of results are consistent across samples and countries, with F-tests yielding no significant differences in the estimated coefficients of clinical expertise. To simplify comparisons, we have z-standardised the dependent variables. Clustered SEs are given in parentheses.

The regression equations show that outcome variables are strongly related to line managers' clinical expertise. In column 1 of table 3 , for example, the coefficient on the level of clinical expertise of the manager enters a Danish physician's job satisfaction equation with a coefficient of 0.29 . To put this into context, it implies that physicians who have a line manager who is high on clinical expertise tend, other things held constant, to have a level of job satisfaction that is approximately one-third of an SD higher than those who do not.

Encouragingly, to correct for potential personality effects, an adjustment for satisfaction with life at home makes almost no

Table 1 The characteristics of the physicians in the three samples of hospitals' (Denmark, Australia and Switzerland) mean, SD, correlation coefficients and coefficient alphas of dependent and explanatory variables

\begin{tabular}{|c|c|c|c|c|c|c|c|}
\hline & Mean & SD & 1 & 2 & 3 & 4 & 5 \\
\hline \multicolumn{8}{|l|}{ Sample 1 ( $n=2264)$} \\
\hline Job satisfaction (single item) & 4.32 & 1.35 & - & & & & \\
\hline Job satisfaction (scale) & n.a.t & n.a. $\ln ^{-}$ & - & - & & & \\
\hline Intention to quit (inverse) & 3.34 & 1.55 & $0.31 * * *$ & - & - & & \\
\hline Global transformational leadership & 23.71 & 6.76 & $0.32 * * *$ & - & $0.30^{* * *}$ & $(0.94)$ & \\
\hline Line manager is a clinical expert & 0.58 & 0.49 & $0.16^{* * *}$ & - & $0.12^{* * *}$ & $0.39 * * *$ & - \\
\hline \multicolumn{8}{|l|}{ Sample $2(n=335)$} \\
\hline Job satisfaction (single item) & 3.74 & 1.35 & - & & & & \\
\hline Job satisfaction (scale) & 33.23 & 7.61 & $0.77 * * *$ & $(0.88)$ & & & \\
\hline Intention to quit (inverse) & 2.89 & 1.63 & $0.50 * * *$ & $0.55^{* * *}$ & - & & \\
\hline Global transformational leadership & 23.53 & 7.85 & $0.32 * * *$ & $0.50^{* * *}$ & $0.31^{* * *}$ & $(0.97)$ & \\
\hline Line manager is a clinical expert & 0.61 & 0.49 & $0.12^{*}$ & $0.20 * * *$ & $0.11 *$ & $0.54^{* * *}$ & - \\
\hline \multicolumn{8}{|l|}{ Sample $3(n=315)$} \\
\hline Job satisfaction (single item) & 3.59 & 1.36 & - & & & & \\
\hline Job satisfaction (scale, $n=158$ ) & 34.39 & 5.57 & $0.34^{* * *}$ & $(0.81)$ & & & \\
\hline Intention to quit (inverse, $\mathrm{n}=155$ ) & 2.21 & 1.39 & $0.28 * * *$ & n.a.ł & - & & \\
\hline Global transformational leadership & 17.31 & 4.54 & $0.26 * * *$ & $0.66 * * *$ & $0.42 * * *$ & $(0.91)$ & \\
\hline Line manager is a clinical expert & 0.68 & 0.47 & $0.12^{*}$ & $0.33^{* * *}$ & $0.22 * * *$ & $0.41 * * *$ & - \\
\hline
\end{tabular}

Coefficient (Cronbach's) alpha on constructs in parentheses.

${ }^{*} p<0.05,{ }^{* *} p<0.01,{ }^{* * *} p<0.001$.

†The generic job satisfaction scale was not collected in the Denmark sample.

¥Nobody filled out both; respondents were randomised to either fill out the scale or the intention to quit. 
Table 2 Demographics of physicians in the three samples' means and SDs of demographical variables

\begin{tabular}{|c|c|c|c|c|c|c|}
\hline & \multicolumn{2}{|c|}{$\begin{array}{l}\text { Sample 1: } \\
\text { Denmark } \\
(\mathrm{n}=2264)\end{array}$} & \multicolumn{2}{|c|}{$\begin{array}{l}\text { Sample 2: } \\
\text { Australia } \\
(\mathrm{n}=335)\end{array}$} & \multicolumn{2}{|c|}{$\begin{array}{l}\text { Sample 3: } \\
\text { Switzerland } \\
(\mathrm{n}=315)\end{array}$} \\
\hline & Mean & SD & Mean & SD & Mean & SD \\
\hline \multicolumn{7}{|l|}{ Job position } \\
\hline Intern & 0.06 & 0.23 & 0.03 & 0.17 & n.a. & n.a. \\
\hline Registrar & 0.19 & 0.39 & 0.15 & 0.35 & 0.40 & 0.49 \\
\hline Consultant & 0.13 & 0.34 & n.a. & n.a. & 0.42 & 0.49 \\
\hline $\begin{array}{l}\text { Consultant with } \\
\text { management } \\
\text { responsibility }\end{array}$ & 0.40 & 0.49 & 0.62 & 0.49 & 0.15 & 0.36 \\
\hline $\begin{array}{l}\text { Head of } \\
\text { department/unit }\end{array}$ & 0.06 & 0.24 & 0.14 & 0.35 & 0.01 & 0.08 \\
\hline Medical director & n.a. & n.a. & 0.02 & 0.13 & n.a. & n.a. \\
\hline Executive director & 0.00 & 0.06 & n.a. & n.a. & n.a. & n.a. \\
\hline Other positions & 0.14 & 0.34 & 0.05 & 0.22 & 0.03 & 0.17 \\
\hline $\begin{array}{l}\text { Years in current } \\
\text { position }\end{array}$ & 6.65 & 6.45 & 9.96 & 8.76 & 4.58 & 4.02 \\
\hline $\begin{array}{l}\text { Hours worked per } \\
\text { week }\end{array}$ & 42.76 & 8.67 & 40.08 & 17.17 & 57.56 & 11.77 \\
\hline Age & 48.15 & 11.36 & 47.57 & 11.55 & 39.13 & 8.72 \\
\hline Gender ( $1=$ female) & 0.53 & 0.50 & 0.49 & 0.50 & 0.44 & 0.50 \\
\hline Gender (1=others) & 0.00 & 0.04 & 0.01 & 0.09 & 0.02 & 0.13 \\
\hline
\end{tabular}

difference to the size of the estimated clinical expertise coefficient (column 2). An equivalent finding is evident in columns 3 and 4 of table 3 . Those physicians who rate their manager's expertise as high are less likely to want to quit their job (with a coefficient of 0.29 in column 3). They also, in columns 5 and 6 of table 3 , rate their manager as a more transformational leader. This estimated effect is large: approximately three-quarters of an SD (as in 0.77 in column 5 of table 3 ).

Tables 4 and 5, for the Australian and the Swiss samples, produce similar conclusions to those in table 3 for Denmark. In these cases, it is also possible, as a check, to use a multi-item measure of job satisfaction (in model 2 of each table, where it can be seen that the implied effect size of clinical expertise on job satisfaction tends to become even larger when measuring job satisfaction with a scale instead of a single item).

Once again, in tables 4 and 5, the sampled physicians' quit likelihood depends-inversely — on the clinical expertise of their boss. In table 4 , model 3 , the effect size is approximately onequarter of an SD. In table 5, model 3, it is estimated at a little less than a half of an SD. The healthcare systems in Australia and Switzerland are not identical, of course, and those differences may play a role in the determinants of these effect sizes. Another explanation is that the Swiss hospitals all represented highly attractive places to work, so that in the absence of other determinants of quit intentions, line managers played a bigger role.

Model 4 in tables 4 and 5 presents results on perceptions of line managers' leadership behaviour. Consistently, we find that physicians who perceive their line manager as an expert clinician rate the transformational leadership behaviour of their line manager significantly higher than those who do not have a manager with high clinical expertise.

\section{DISCUSSION}

This paper finds that line managers' clinical expertise is positively associated with employees' job satisfaction and quit intentions. This relationship is also found beyond the hospital sector, in studies that highlight the role of boss competence ${ }^{28} 30$ and in earlier work that examines the influence of leaders on physicians' quit intentions in hospitals. ${ }^{31}$ At the broadest level, this study's finding, which is about the influence of line managers, also builds on existing literature that shows a robust association between - at the very top of organisations-CEOs' level of professional expertise and organisational outcomes. ${ }^{1-6}$

While this article is not about the COVID-19 pandemic, that crisis has further propelled medical doctors into leadership positions and brought into focus the importance of ensuring that nations have well-functioning hospitals. Our key empirical finding is potentially a practical one: the correlational evidence in this article suggests that the clinical expertise of line managers

Table 3 Physicians' job satisfaction, likelihood to quit and assessment of their manager's leadership behaviour in sample 1 (Denmark)

\begin{tabular}{|c|c|c|c|c|c|c|}
\hline \multirow[b]{3}{*}{ Line manager is a clinical expert $†$} & \multirow{2}{*}{\multicolumn{2}{|c|}{$\begin{array}{l}1 \\
\begin{array}{l}\text { Job satisfaction (single item) z- } \\
\text { standardised }\end{array}\end{array}$}} & \multicolumn{2}{|l|}{2} & \multicolumn{2}{|l|}{3} \\
\hline & & & \multicolumn{2}{|c|}{ Inverted quit intention z-standardised } & \multicolumn{2}{|c|}{$\begin{array}{l}\text { Transformational leadership behaviour } \\
\text { z-standardised }\end{array}$} \\
\hline & $0.29 * * *(0.04)$ & $0.26^{* * *}(0.04)$ & $0.29^{* * *}(0.04)$ & $0.29 * * *(0.04)$ & $0.77^{* * *}(0.05)$ & $0.77^{* * *}(0.05)$ \\
\hline Job position dummies $\ddagger$ & Yes & Yes & Yes & Yes & Yes & Yes \\
\hline Years in position & $-0.01(0.01)$ & $-0.01(0.01)$ & $0.02^{* *}(0.01)$ & $0.02^{* *}(0.01)$ & $-0.00(0.01)$ & $-0.00(0.01)$ \\
\hline Hours worked per week & $-0.00(0.00)$ & $-0.00(0.00)$ & $-0.01 *(0.00)$ & $-0.01 *(0.00)$ & $-0.00(0.00)$ & $-0.00(0.00)$ \\
\hline Gender ( $1=$ others) & $-0.19 *(0.08)$ & $0.19(0.44)$ & $0.22(0.34)$ & $0.25(0.34)$ & $-0.15(0.18)$ & $-0.11(0.22)$ \\
\hline Satisfaction with life at home & - & $0.35^{* * *}(0.02)$ & - & $0.02(0.02)$ & - & $0.04 *(0.02)$ \\
\hline Constant & $-0.24(0.19)$ & $-1.67^{* * *}(0.20)$ & $-0.27(0.24)$ & $-0.35(0.24)$ & $0.14(0.21)$ & $-0.01(0.21)$ \\
\hline Number of observations & 2264 & 2264 & 2264 & 2264 & 2264 & 2264 \\
\hline Number of clusters & 168 & 168 & 168 & 168 & 168 & 168 \\
\hline
\end{tabular}

Clustered SEs in parentheses.

${ }^{*} \mathrm{p}<0.05,{ }^{* *} \mathrm{p}<0.01,{ }^{* * *} \mathrm{p}<0.001$

tThe variable 'Line manager is a clinical expert' is a dummy variable that takes the value of one when the physician's immediate senior is rated in the top-two categories (and a value of 0 otherwise) using the following assessment: My immediate senior is 'a highly distinguished clinician' 'a distinguished clinician', 'an averagely able clinician'. 'not that interested in clinical work', 'not a clinician' and 'others (please specify)'.

¥The job position dummies are the job grades listed in table 2 . 
Table 4 Physicians' job satisfaction, likelihood to quit and assessment of their manager's leadership behaviour in sample 2 (Australia)

\begin{tabular}{|c|c|c|c|c|}
\hline & 1 & 2 & 3 & 4 \\
\hline & $\begin{array}{l}\text { Job satisfaction (single item) } \\
\text { z-standardised }\end{array}$ & $\begin{array}{l}\text { Job satisfaction (scale) z- } \\
\text { standardised }\end{array}$ & $\begin{array}{l}\text { Inverted quit intention z- } \\
\text { standardised }\end{array}$ & $\begin{array}{l}\text { Transformational leadership } \\
\text { behaviour z-standardised }\end{array}$ \\
\hline Line manager is a clinical expert $†$ & $0.24^{*}(0.11)$ & $0.43^{* * *}(0.11)$ & $0.26^{*}(0.13)$ & $1.09 * * *(0.15)$ \\
\hline Job position dummies $\ddagger$ & Yes & Yes & Yes & Yes \\
\hline Years in position & $-0.02 * *(0.01)$ & $-0.03^{* *}(0.01)$ & $-0.01(0.01)$ & $-0.01(0.01)$ \\
\hline Hours worked per week & $-0.00(0.00)$ & $0.00(0.00)$ & $-0.01^{*}(0.00)$ & $0.01(0.01)$ \\
\hline Age & $0.02 *(0.01)$ & $0.03^{* *}(0.01)$ & $0.00(0.01)$ & $0.01(0.01)$ \\
\hline Gender (1=female) & $-0.01(0.10)$ & $0.031(0.09)$ & $-0.20(0.12)$ & $0.14(0.07)$ \\
\hline Gender (1 =others) & $-0.37(0.68)$ & $-0.17(0.51)$ & $0.48(0.30)$ & $-0.31(0.24)$ \\
\hline Constant & $-0.95^{*}(0.52)$ & $-1.33^{* *}(0.38)$ & $0.059(0.29)$ & $-1.34^{* *}(0.39)$ \\
\hline Number of observations & 335 & 335 & 335 & 335 \\
\hline Number of clusters & 43 & 43 & 43 & 43 \\
\hline $\mathrm{F}$ & 3.66 & 7.05 & 5.42 & 49.50 \\
\hline$R^{2}$ & 0.07 & 0.08 & 0.05 & 0.33 \\
\hline
\end{tabular}

Clustered SEs in parentheses.

${ }^{*} \mathrm{p}<0.05,{ }^{* *} \mathrm{p}<0.01,{ }^{* *} \mathrm{p}<0.001$.

tThe variable 'Line manager is a clinical expert' is a dummy variable that takes the value of one when the physician's immediate senior is rated in the top-two categories (and a value of 0 otherwise) using the following assessment: My immediate senior is 'a highly distinguished clinician', 'a distinguished clinician', 'an averagely able clinician', 'not that interested in clinical work', 'not a clinician' and 'others (please specify)'.

¥The job position dummies are for the job grades listed in table 2 .

in hospitals matters for the well-being of the physicians whom they supervise. It appears that it is not sufficient merely for the supervisors of clinicians to themselves be clinicians (that is automatically true of almost all the individuals and hospitals sampled for the analysis in this article). This article's emphasis on clinical expertise thus sits in contrast with the notion that those who choose to become managers are likely to be the less competent physicians. ${ }^{32}$ Instead, the message from these results seems clear: the sheer level of clinical ability of a line manager appears to matter for the job satisfaction and consequent productivity, of those they manage. Physicians want to be led by outstanding experts. This may partly be explained by the finding of Spehar et $a l^{33}$ that physician managers use their medical expertise to lead.

What are the implications of this study for policy and people development? Physicians considered to be among the best in their field might view a step into management as a step too far away from their expertise, instead of an expansion of it (by potentially influencing a larger body of patients than is possible for a single clinician to treat). In many healthcare systems, managers' pay is lower than the remuneration a top clinician can receive. A recent study assessed both physicians' incentives and disincentives linked to taking a management position. ${ }^{34} \mathrm{~A}$ first policy suggestion would be to ensure that the incentives are properly in place to motivate expert physicians into leadership.

A second proposition is tied to staff development. One motivating factor identified by Bäker $e t a l^{34}$ was to offer management and leadership training to physicians. Leadership development programmes designed for the specific needs of physicians are rare compared with the wealth of training courses that have been available for nurses for many years. Therefore, we would

Table 5 Physicians' job satisfaction, likelihood to quit and assessment of their manager's leadership behaviour in sample 3 (Switzerland)

\begin{tabular}{|c|c|c|c|c|}
\hline & 1 & 2 & 3 & 4 \\
\hline & $\begin{array}{l}\text { Job satisfaction (single item) } \\
\text { z-standardised }\end{array}$ & $\begin{array}{l}\text { Job satisfaction (scale) z- } \\
\text { standardised }\end{array}$ & $\begin{array}{l}\text { Inverted quit intention z- } \\
\text { standardised }\end{array}$ & $\begin{array}{l}\text { Transformational leadership } \\
\text { behaviour z-standardised }\end{array}$ \\
\hline Line manager is a clinical expert† & $0.28(0.17)$ & $0.61^{* *}(0.20)$ & $0.46^{* *}(0.15)$ & $0.97^{* * *}(0.13)$ \\
\hline Job position dummies $\ddagger$ & Yes & Yes & Yes & Yes \\
\hline Years in position & $0.00(0.04)$ & $0.03(0.03)$ & $0.02(0.03)$ & $-0.01(0.03)$ \\
\hline Hours worked per week & $-0.02 * *(0.00)$ & $-0.01(0.01)$ & $0.00(0.01)$ & $-0.02^{* *}(0.01)$ \\
\hline Gender ( $1=$ others $)$ & $-0.90^{* * *}(0.20)$ & $0.12(0.26)$ & $-0.73(0.48)$ & $-0.25(0.26)$ \\
\hline Constant & $0.30(0.59)$ & $0.24(0.81)$ & $-0.27(0.62)$ & $0.62(0.57)$ \\
\hline Number of observations & 315 & 158 & 155 & 315 \\
\hline Number of clusters & 31 & 26 & 25 & 31 \\
\hline $\mathrm{F}$ & 10.99 & - & - & 13.97 \\
\hline
\end{tabular}

Clustered SEs in parentheses.

${ }^{*} p<0.05,{ }^{* *} p<0.01,{ }^{* * *} p<0.001$.

tThe variable 'Line manager is a clinical expert' is a dummy variable that takes the value of one when the physician's immediate senior is rated in the top-two categories (and a value of 0 otherwise) using the following assessment: My immediate senior is 'a highly distinguished clinician', 'a distinguished clinician', 'an averagely able clinician', 'not that interested in clinical work', 'not a clinician' and 'others (please specify)'.

¥The job position dummies are for the job grades listed in table 2. 
encourage the expansion of tailored leadership training, to prepare physicians for middle and senior management, which our research shows can help lead to improved job satisfaction among subordinates. ${ }^{35}$ A final suggestion would be to ensure that these opportunities are open to the diverse body of physicians in our health systems, thus supporting diversity in leadership.

Acknowledgements We thank Andrew Oswald of the University of Warwick for his detailed comments. We are also grateful to Alex Bryson, Brian Harney and Jens Mohrenweiser, as well as the participants in the 'Contemporary Readings on Behaviour in Organisations' group at the University of Zurich in spring 2020, for their helpful comments in developing this article, and to University of Zurich hospitals, the South Australian Salaried Medical Officers Association and the Organization of Danish Medical Societies for the opportunity to survey their doctors.

Contributors AB planned the study, designed the survey, conducted the data collection, cleaned and analysed the data, wrote the empirical sections and contributed to the writing on the other sections and the finalisation of the revised manuscript. She guarantees the overall content. AHG planned the study, designed the survey, set up the paper storyline and wrote the first draft of the paper (excluding the empirical sections), led the revision redrafting process and managed the submission. She guarantees the overall content.

Funding The authors have not declared a specific grant for this research from any funding agency in the public, commercial or not-for-profit sectors.

Competing interests None declared.

Patient consent for publication Not required.

Ethics approval Approval was obtained for each study at the ethics committee of the Faculty of Business, Economics and Informatics at the University of Zurich.

Provenance and peer review Not commissioned; externally peer reviewed.

Data availability statement Data are available in a public, open-access repository. Data are available upon reasonable request. Our data are available to anyone who requests them.

ORCID iD

Amanda H Goodall http://orcid.org/0000-0002-9074-1157

\section{REFERENCES}

1 De Regge M, Eeckloo K. Balancing Hospital governance: a systematic review of 15 years of empirical research. Soc Sci Med 2020;262:113252.

2 Tasi MC, Keswani A, Bozic KJ. Does physician leadership affect Hospital quality, operational efficiency, and financial performance? Health Care Manage Rev 2019:44:256-62.

3 Goodall AH. Physician-leaders and hospital performance: is there an association? Soc Sci Med 2011;73:535-9.

4 Sarto F, Veronesi G. Clinical leadership and hospital performance: assessing the evidence base. BMC Health Serv Res 2016;16 Suppl 2:169.

5 Veronesi G, Kirkpatrick I, Vallascas F. Clinicians on the board: what difference does it make? Soc Sci Med 2013;77:147-55.

6 Kakemam E, Goodall AH. Hospital performance and clinical leadership: new evidence from Iran. BMJ Leader 2019;3:108-14.

7 Duffield C, Gardner G, Doubrovsky A, et al. Manager, clinician or both? nurse managers' engagement in clinical care activities. J Nurs Manag 2019;27:1538-45.

8 Lin BY-J, Hsu C-PC, Juan C-W. The role of leader behaviors in hospital-based emergency departments' unit performance and employee work satisfaction. Soc Sci Med 2011;72:238-46.
9 Robson A, Robson F. Investigation of nurses' intention to leave: a study of a sample of UK nurses. J Health Organ Manag 2016;30:154-73.

10 Wade GH, Osgood B, Avino K, et al. Influence of organizational characteristics and caring attributes of managers on nurses' job enjoyment. J Adv Nurs 2008;64:344-53.

11 Guest DE. Human resource management and employee well-being: towards a new analytic framework. Hum Resour Manag J 2017;27:22-38.

12 Böckerman P. IImakunnas P. The job satisfaction-productivity nexus: a study using matched survey and register data. ILR Rev 2012;65:244-62.

13 Bryson A, Forth J, Stokes L. Does employees' subjective well-being affect workplace performance? Hum Relat 2017:70:1017-37.

14 Oswald AJ, Proto E, Sgroi D. Happiness and productivity. J Labor Econ 2015;33:789-822.

15 Hom PW, Griffeth RW, Sellaro CL. The validity of Mobley's (1977) model of employee turnover. Organ Behav Hum Perform 1984;34:141-74.

16 Shanafelt TD, Gorringe G, Menaker R, et al. Impact of organizational leadership on physician burnout and satisfaction. Mayo Clin Proc 2015;90:432-40.

17 Halbesleben JRB, Rathert C. Linking physician burnout and patient outcomes: exploring the dyadic relationship between physicians and patients. Health Care Manage Rev 2008;33:29-39.

18 Nørøxe KB, Pedersen AF, Bro F, et al. Mental well-being and job satisfaction among general practitioners: a nationwide cross-sectional survey in Denmark. BMC Fam Pract 2018;19:130.

19 Kulik CT, Perry EL. When less is more: The effect of devolution on HR's strategic role and construed image. Hum Resour Manag 2008:47:541-58.

20 Simsek Z, Veiga JF. The electronic survey technique: an integration and assessment. Organ Res Methods 2000:3:93-115.

21 Wanous JP, Reichers AE, Hudy MJ. Overall job satisfaction: how good are single-item measures? J Appl Psychol 1997:82:247-52.

22 Macdonald S, Maclntyre P. The generic job satisfaction scale: scale development and its correlates. Emp/ Assist Q 1997;13:1-16.

23 Carless SA, Wearing AJ, Mann L. A short measure of transformational leadership. J Bus Psychol 2000;14:389-405.

24 Leroy H, Segers J, Van Dierendonck D. Managing people in organisations: integrating the study of HRM and leadership. Hum Resour Manag Rev 2018;28:249-57.

25 Currie G, Burgess N, Hayton JC. Hr practices and knowledge brokering by hybrid middle managers in hospital settings: the influence of professional hierarchy. Hum Resour Manag 2015:54:793-812.

26 Russell ZA, Steffensen DS, Ellen BP, et al. High performance work practice implementation and employee impressions of line manager leadership. Hum Resour Manag Rev 2018;28:258-70.

27 Robie C, Ryan AM, Schmieder RA, et al. The relation between job level and job satisfaction. Group Organ Manag 1998;23:470-95.

28 Bäker A, Goodall AH. Feline followers and "umbrella carriers": Department Chairs' influence on faculty job satisfaction and quit intentions. Res Policy 2020;49:103955.

29 Podsakoff PM, MacKenzie SB, Lee J-Y, et al. Common method biases in behavioral research: a critical review of the literature and recommended remedies. J Appl Psychol 2003;88:879-903

30 Artz BM, Goodall AH, Oswald AJ. Boss competence and worker well-being. ILR Rev 2017;70:419-50

31 Martinussen PE, Magnussen J, Vrangbæk K, et al. Should I stay or should I go? The role of leadership and organisational context for hospital physicians' intention to leave their current job. BMC Health Serv Res 2020;20:400.

32 Llewellyn S. Two-Way Windows': Clinicians as Medical Managers. Organ Stud 2001:22:593-623.

33 Spehar I, Frich JC, Kiekshus LE. Clinicians in management: a qualitative study of managers' use of influence strategies in hospitals. BMC Health Serv Res 2014;14:251

34 Bäker A, Bech M, Geerts J. What would motivate doctors into leadership and management roles? New survey evidence from Denmark. BMJ Leader 2020:4:196-200

35 Geerts JM, Goodall AH, Agius S. Evidence-based leadership development for physicians: a systematic literature review. Soc Sci Med 2020;246:112709. 